\title{
Geochemical Features of Cretaceous Crude Oil and Oil-Source Correlation in Guaizihu Sag, Yin'gen-E'ji'naqi Basin, China
}

\author{
WANG PING ${ }^{1}$, JIANG HAIJIAN ${ }^{1}$, CHEN QINGTANG $^{2}$, \\ SHI DAHAI ${ }^{2}$
}

${ }^{1}$ Wuxi Research Institute of Petroleum Geology, SINOPEC, Wuxi, Jiangsu 214126, China

${ }^{2}$ Zhongyuan Oil Field Branch Company, SINOPEC, Puyang, Henan 457000, China

Recently, high oil product was gained in $\mathrm{K}_{1} b_{2}$ of well $X$ in the Guaizihu Sag of Yin'gen-E'ji'naqi Basin, China,which revealed a bright exploration prospect. Analyses of compositions, biomarkers and carbon isotopes were made with $\mathrm{K}_{1} s_{1}$ oil sand samples, $\mathrm{K}_{1} b_{2}$ crude oil and mudstone samples from $\mathrm{K}_{1} s_{2}, \mathrm{~K}_{1} b_{1}$ and $\mathrm{K}_{1} b_{2}$. The geochemical features of oil sands, crude oil are close with $\mathrm{K}_{1} b_{1}$ source rocks, showing high contents of $\mathrm{C}_{30}$-diahopane and gammacerane, low $\mathrm{Pr} / \mathrm{Ph}$ and high maturity. The good similarity reflects that $\mathrm{K}_{1} s_{1}$ oil sands and $\mathrm{K}_{1} b_{2}$ oil are homologous, and their parent material are both from $\mathrm{K}_{1} b_{1}$ source rocks. This research results is bound to be helpful for the prediction of hydrocarbon reservoir and the selection of exploration direction for this area.

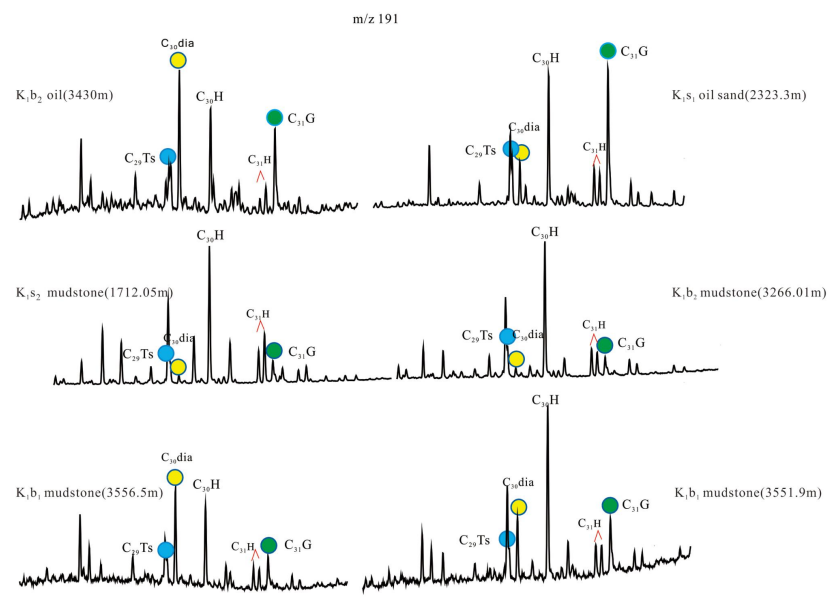

Fig.1 Saturates gas chromatography-mass spectrogram of oil sands, crude oil and source rocks in well X, Guaizihu Sag, Yin'gen-E'ji'naqi Basin,China. 